\title{
Organic Monadology in Maupertuis
}

\author{
Maurício de Carvalho Ramos \\ Departamento de Filosofia, Universidade de São Paulo, São Paulo, Brazil \\ Email: maucramos@gmail.com
}

Received 3 February 2015; accepted 17 February 2015; published 30 March 2015

Copyright (C) 2015 by author and Scientific Research Publishing Inc.

This work is licensed under the Creative Commons Attribution International License (CC BY).

http://creativecommons.org/licenses/by/4.0/

(c) (i) Open Access

\begin{abstract}
The present paper aims to define the seminal parts in the generation theory in Pierre-Louis Moreau de Maupertuis's System of nature as Leibnizian physical monads of a special type, organic monads, whose main characteristics are: 1) uniting, within the same explanatory system, epigenesis and preformation, following from an interpretation where initial conditions for epigenesis are a homogenous, non-organic seminal matter; 2) having psychic properties which give them a preformational character, allowing seminal parts to display a combination of material and representational morphologies, elaborated from a distinction between the substantial and relational character of chemical affinities proposed by François-Geoffroy; 3) bringing, through the previous two characteristics, the System of nature to intelligibly express preexistence, a concept present in Maupertuis' conjectures on the origins of the first organisms, where to a strongly naturalistic scenario, a supernatural cause is added-one consistent, within limits, with the natural indestructibility of the physical monad within a panspermic reading of the original Leibnizian monadology. Together, these characteristics allow us to define Maupertuis's generation theory as an organic monadology, capable of expressing itself in other components of the modern sciences of life and the organic, revealing a historical continuity for the heuristics of Leibniz's natural philosophy.
\end{abstract}

\section{Keywords}

Organic Monad, Maupertuis, Monadology, Epigenesis, Preformation, Chemical Affinity

\section{Introduction: The Evaluation of Maupertuis Theories of Organic Generation of Antiquity}

Pierre-Louis Moreau de Maupertuis developed a set of conjectures to explain certain aspects of organic generation that challenged the natural science and philosophy of the eighteenth century. The problem of generation was expressed as a web of relatively complex, integrated ontogenetic (that is, concerning development, reproduction and the life cycle) and phylogenetic (related to the origin, stabilization and mutation of genealogies, races and species) phenomena which were, in turn, related to methodological and epistemological problems. One of Mau- 
pertuis' most important advances in this direction was the way he conceived and used the fundamental and, at first glance, antagonistic genetic concepts of epigenesis and preformation. In the present study I examine these assumptions so as to, ultimately, characterize the theory of generation of Maupertuis as a kind of organic monadology that renders intelligible an alliance between epigenesis and preformation, and likewise certain aspects of the concept of germ preexistence.

The conceptual tension between epigenesis and preformation may be variously interpreted, depending on how one articulates the multiple elements that comprise each of the concepts. What we have is a matrix of theoretical components expressed throughout history that, differently combined, might confer some degree of unity to the two concepts in opposition. With this in mind, I will begin by analyzing how Maupertuis adopts and interprets, in Vénus physique (1745), certain concepts derived from Antiquity. To this end, I propose to fix, within the specific scope of this article, some concepts and terms around the theme of organic generation. The first of these refers to the process that gives rise to the seed, the semen or seminal parts, and which I call spermatogenesis ${ }^{1}$. In some Hippocratic and atomistic conceptions, the semen comes from all the parts of each parent's body ${ }^{2}$. As a consequence, the general physiology of the organism is endowed, in an integrated fashion, with functions that can be conceived separately as somatic and germinal. To spermatogenesis conceived in these terms I give the name pangenesis. The establishment of the initial conditions for embryogenesis, a process specifically understood as the generation of the embryo ${ }^{3}$, occurs when, after copulation, the male and female semen come together in the womb. I refer to this particular set of phenomena with the expression mixture of the seeds. These notions are opposed to Aristotelian conceptions about the generation of organisms. There, spermatogenesis does not occur by pangenesis, but by means of the digestion of blood, so the prolific power is restricted to organs and processes responsible for this function ${ }^{4}$. The initial condition for embryogenesis is not the mixture of the two seeds, but the hylemorphic combination of formal male and material female principles ${ }^{5}$. This association clearly differs from a mixture of seeds, since only the paternal contribution has a dynamic and prolific power.

In constructing his own theory of organic generation, Maupertuis chooses and combines these concepts into a simplified synthesis he refers to as the system of the ancients ${ }^{6}$ :

For centuries on end this system satisfied philosophers, for, while there was some diversity of belief among them stemming from the fact that some held only one of the two liquids as true prolific matter, while the other merely served the purpose of feeding the fetus, they were all in agreement on these two liquids, and on attributing to their mixture the great work of generation ${ }^{7}$.

The mixture of the seeds, then, is the generative process to be adopted as the starting point for further investigation. An examination of these ancient conceptions, however brief, can help us identify some essential distinctions to be made. For instance, when spermatogenesis takes place by means of pangenesis, the seeds necessarily undergo an elaboration which makes them pre-differentiated. Thus, the initial condition of embryogenesis is presented as an organically or morphologically heterogeneous structure. Regardless of the nature and degree of this differentiation, I believe pangenetic elaboration to invariably involve a preformation of parts, as opposed to the widespread conception of the preformation of the whole embryo before copulation. In the Aristotelian conception, the opposite occurs. The preparation of the seed from the digestion of the blood does not imply this sort of preformation, too lacking in feminine nutritive matter. Thus, the initial state of embryogenesis must be regarded as homogenous. This difference is even greater when we consider embryogenesis itself. The formation of the embryo from this seminal homogenous state takes place by epigenesis. Generation occurs through a process in which a formal and internal seminal principle of organization progressively modifies a material substratum, producing differentiations in succession, organ after $\operatorname{organ}^{8}$, ultimately producing a body whose final structure

\footnotetext{
${ }^{1}$ A preservation of the historical acceptation of the term being our specific aim, the concept of spermatogenesis should not be understood in its current, cytogenetic sense of the production of male gametes or sex cells.

${ }^{2}$ Hippocrates (1981: p. 1; 1992: p. 151).

${ }^{3}$ The continuity between embryogenesis and the postnatal development of the organism is a problematic issue for a considerable part of the theories and concepts concerning the generation of organisms. The soma-germ union or separation involves complex relationships between organic constitution and generation. An instance of this relationship may be found in Anaxagoras.

${ }^{4} \mathrm{~A}$ comprehensive and accurate overview of the tension between pangenesis and the views of Aristotle may be found in Smith (2006: pp. 3-6). ${ }^{5}$ (Generation of animals, I.20, 729a 8-30; I.21, 730a 25). Aristotle (1953).

${ }^{6}$ The brief and selective way in which Maupertuis refers to the ancients also appears in his studies of mechanics and optics. I believe this to consist in a typically scientific use of the history of science. He consults Aristotle, Harvey and the then recent work published in Mémoires de l'Académie des Sciences as scientific sources possessing equal cognitive value.

${ }^{7}$ Maupertuis (1965 [1768]: p. 12).

${ }^{8}$ (On the generation of animals, II.1, 734a17-734b42). Aristotle (1953).
} 
mirrors its own.

\section{Preformation, Chemical Affinities and the Metallic Trees}

From the aforementioned notions, Maupertuis adopts, in addition to the basic process of the mixture of the seeds, pangenesis and generation by aggregation. A consequence of that is the incorporation of the idea of preformation of the seminal parts into his conjectures. The process of aggregation, however, is conceived and explained through modern theoretical elements derived from Newtonian-based chemistry, foremost among them the concept of attraction as an explanation for chemical reactions ${ }^{9}$. For Maupertuis, "when one says that a fetus is formed by the mixture of the two seeds, one is far from having explained such a formation”, ${ }^{\text {. }}$. The important thing is to understand the internal mechanism that brings the preformed seminal parts together in such a way that an organism results which possesses the same specific structure its ancestors possessed. For that end, Maupertuis' strategy was to look for an analogy capable of bringing into evidence the existing commonalities between the mixture of reactive substances present in ordinary chemical phenomena, and the mixture of the-equally reactive-seminal liquids of organisms: "When silver and spirit of nitre are mixed with mercury and water, the arborescence the parts of these matters arrange themselves into is so much like a tree, that one cannot begrudge it that name" $" 11$.

The arborescence in question is known as Diana's tree, or silver tree, a kind of artificial crystallization the morphogenesis of which, according to Maupertuis, may be accounted for by an appeal to the action of special attractive forces, namely chemical affinities. Originally postulated by Etienne-François Geoffroy, such affinities may be interpreted as the bonding forces present in bodies and substances, the actions of which are differentiated in a qualitative fashion. Unlike the force of universal attraction, chemical affinities are conceived as capable of acting selectively, in accordance with the substances involved. For that reason, it is my understanding that such affinities exhibit a teleological character, which may be seen in the way Geoffroy explains the way affinities behave in the phenomena of chemical composition and decomposition:

I have observed that, among the substances possessing this disposition for connection, when two of them are united, some [substances] that approach them or merge with them, bond to one of the two and repel the other; and [other substances] do not bond with either, and do not separate them. Thus, it seemed to me we could plausibly conclude that those which join with one of the two had a greater tendency or disposition to bond with that particular substance than with the one that was repelled by its approach ${ }^{12}$.

Affinity is a disposition whose meaning, as I understand it, involves the acceptance of some sort of internal quality of substances. Under many aspects, however, it is also a concept that operates in a relational way, that is, one that defines chemical substances and their properties from a kind of combinatory rule. Geoffroy attempted to generalize and systematize these rules for the relations between substances with his widely known Table des différens rapports observés en Chimie entre différentes substances (1718). It consists of sixteen columns, with the symbol for a different given substance placed at the top of each. Under each symbol, additional symbols for the substances that react with the one at the top of the list may be found; the farther away from the top a substance appears, the weaker is its relation to the one at the top. Below, I will discuss the relation that exists between these two ways of interpreting the dispositions integrated with the affinities. By associating such dispositions to the concept of the mixture of the seeds, Maupertuis elaborated his first conjectural model of organic generation:

[...] there being, within each and every seed, parts destined to form the heart, the head, the entrails, the arms and the legs, and each part having a greater binding relation with another which, for the formation of the animal, must be its neighbor, than with all others: the fetus will be formed, and it would still be formed even if it were a thousandfold more organized than it is ${ }^{13}$.

Making use of the terms and concepts which I have presented above, my brief characterization of that initial model is as follows: a pangenesis-derived spermatogenesis produces a seed containing preformed, heterogene-

\footnotetext{
${ }^{9}$ Mocellin, 2006; Metzger, 1974: pp. 34-68.

${ }^{10}$ Maupertuis (1965 [1768]: p. 84).

${ }^{11}$ Maupertuis (1965 [1768]: p. 86).

${ }^{12}$ Geoffroy (1770: p. 149).

${ }^{13}$ Maupertuis (1965 [1768]: p. 133).
} 
ous parts; each progenitor, male and female, produces his or her own seed. The starting condition for embryogenesis is established by the mixture of the seeds, and the generation of the embryo occurs by means of an aggregation of seminal parts endowed with intrinsic dispositions. Such dispositions are Newtonian forces in the guise of chemical affinities whose differentiated activities must somehow be intimately connected to organic morphological differences. The creation of a theoretical space consistent with such a model where a notion of organic affinity is understood as a special morphological force is, then, entirely possible. Judging, however, by the degree to which Maupertuis is committed to Newtonian physics and methodology, it seems to me that the explanatory power of the analogy between the form of arborescent metallic crystals and that of animals proposed in the Vénus depends on the adoption, at least as an initial assumption, of the reduction of hypothetical organic affinities (or equivalent forces) to chemical affinities as a possibility. In reductions of that kind the simplest expressions of affinity, systematized in Geoffroy's table, could combine to produce second-order attractive and repulsive effects which would act within the various hierarchical levels of organization characteristic of organisms. The same conceptual structure, that is, the multiplication and hierarchization of affinities, is applicable to the development of the very notion of special Newtonian attraction. In Bergman’s Traité des affinités chymiques ou attractions électives the problem of the existence of laws of attraction possessing different degrees of generality is presented by the distinction made between distant and near attractions:

The Illustrious Newton has clearly demonstrated that large bodies in the universe exert their attraction with a force in direct ratio to their masses and in inverse ratio to the square of their distances. Yet the observable tendency towards union that exists in all neighboring bodies seems to follow a very different set of rules when taking place on the Earth's surface. We may call attractions of the latter kind near attraction [attraction prochaine], as they act only over small molecules, and are barely present beyond contact, and name the former, which act over large masses within a vast space, distant attractions [attraction éloignée]. I say the laws governing these two types of attraction seem different from one another, for all the difference may depend on nothing but circumstance ${ }^{14}$.

The addition of this new source of determination to the particular conditions under which the simplest, most ordinary chemical combinations occur is, conceptually, analogous to the morphological determination that is a consequence of pangenetic spermatogenesis. For the author,

[...] the figure and the situation not merely of the whole, but also of each part, produce large variations on the effects of attraction. That way, quantities that would be negligible in distant attractions modify the laws governing near attractions to a considerable degree [...]. Thus, the same force may, depending on the circumstances, produce very different effects ${ }^{15}$.

The figure of chemical molecules corresponds to the form of the seminal parts (which may also be called organic or seminal molecules without any alteration to the content of the concept). If the modulating effect that molecular figures produce over the attractive force is not subsumed into the dynamic scheme of affinities, the relational character will no longer have priority over a structural interiority of the geometric kind, associated to the notion of figure. Moving on to the sphere of organic generation, a modulating effect that is an even stronger determinant may be expected, not for the figure, but for the form of the seminal parts, in such a way that reduction to relational laws begins to give way to a sort of essential, morphological substantiality. That is precisely what the preformational character that conceptually follows the notion of pangenesis consists of. This theoretical scenario creates some continuity between the dispositions of substances present in the organization of simple chemical bodies, complex crystallizations, metallic trees and living organisms. The teleological component can also freely transit within this continuity.

Mocellin believes the idea of affinity to be inapplicable to Geoffroy's proposal, understanding the author's deliberate use of the term relation to have offered the chemistry of his time a more theoretically neutral concept than affinity or attraction and, thus, one more likely to be widely accepted by chemists. Such a concept would also be consistent with a "notion of substance more commonly derived from its properties/qualities, but seen as a composition/combination, while its identity was determined through its neighborhood relationships"16. By presenting such an interpretation, one which differs significantly from my own, I do not mean to get into a dis-

\footnotetext{
${ }^{14}$ Bergman (1788: p. 2).

${ }^{15} \operatorname{Bergman}(1788:$ pp. 2-3).

${ }^{16}$ Mocellin (2011: p. 24). Other historical elements concerning the question can be found in Shank (2008: chapters 2 and 7).
} 
cussion of the epistemological and historical aspects intrinsic to Geoffroy’s concept, but merely to point out an important problem for the theme presently under consideration, related to the substantial-relational opposition. Attractive forces capable of acting over short distances may be postulated so as to establish a network of relations that determine a set of possibilities for combination between various chemical entities. The properties of each substance are defined based on participation in said network, as the latter establishes a "neighborhood" of substances which, in their turn, define a center which confers identity to a particular substance. What I have called the internal disposition of the substance would be, within that interpretation, merely the effect of external dispositions. Checking Geoffroy’s table, we can see how silver has greater affinity with lead than with copper. That means the identity of silver compounds may be restated as variations in their stability as a function of their association with lead and copper compounds. Such an identity is relational in character, as that which constitutes a silver compound is defined by a combinatory order that is extrinsic to it. The same reasoning may be applied towards an understanding of the kind of identity a tree of Diana would have, the latter conceived as a dendrite, a chemical entity much like a complex, arborescent crystal. In principle, the same set of possibilities that defines the identity of a silver compound may define the identity of a tree of Diana. The difference lies in the complexity of the process, since, as we have seen, both the identity and the stability of the aforementioned structure depends on a combination of silver, spirit of nitre, mercury and water. While theoretically possible, the fact that the explanatory power of Geoffroy's table is restricted to simple substitution reactions $(A+B C=A C+B)^{17}$, it would be exceedingly difficult to "calculate", in a relational sense, the neighborhood and the center for a tree of Diana—or any other kind of metallic tree ${ }^{18}$. When this explanatory system is transferred, as Maupertuis would have it, from dendrites to living organisms, a significant conceptual shift occurs. To the extrinsic determination of relationship laws defining the disposition of substances must be added the morphological determination that pangenetic spermatogenesis bestows upon the seminal parts. If the dispositions generated by pangenesis are conceived as organic dispositions associated with organic affinities, it must be decided whether or not the latter are reducible to dispositions of the relational type, as found in chemical affinities. As we shall see, Maupertuis opts, in his Système de la nature, for non-reducibility.

For Maupertuis, the level of organization in the pre-formed seminal parts is relatively high. Even if one has difficulty imagining what a heart particle, for instance, would actually be like, and taking into consideration that Maupertuis was certainly not thinking of "tiny hearts" or anything of the sort, such particles should be able to communicate some organizational property capable of producing, in embryogenesis, that organ's unity and individuality. The same would be applicable to any other organic part and, at the limit, to the entire organism. How could such a property be accounted for? Such considerations are presented so as to bring into evidence the problem Maupertuis found with the use of the elementary teleology of chemistry for explanations of the hierarchical organization of organisms. What we have referred to, above, as second-order repulsive and attractive effects might not be reducible to first-order, so that the familiar problem of reduction from a higher to a lower level of organization would also be present among the forces responsible for organic generation. A revisiting of the Aristotelian concept of epigenesis may assist us in understanding why, due to there being no pre-formation in spermatogenesis, there must be a complete teleological principle of organization and individuation at work from the very beginning of embryogenesis.

A more concrete example of the problem described may be found in a 1710 article by Guillaume Homberg. This chemist knew metallic trees particularly well, and criticized attempts to establish analogies between metallic and organic trees. In his view, the branches of metallic trees

[...] greatly resemble true vegetation when our observations are restricted to the external figure; yet, when we consider that a true plant is an organic body whose parts serve the function of drawing nutrients from the ground, of preparing such nutrients for the sustenance and growth of the plant and, finally, of producing seeds, themselves tiny organic bodies which, by means of the nourishment they absorb, unfold into new plants; and when, conversely, we see that our artificial vegetations consist in simple crystallizations or the gathering of a few small pieces of metal which chance has placed atop one another without order or organic parts, any comparison we may feel inclined to draw between them and the true vegetation of plants will fail to subsist in any meaningful way ${ }^{19}$.

\footnotetext{
${ }^{17}$ Mocellin (2011: p. 24).

${ }^{18} \mathrm{I}$ believe the same reasoning may be used towards an understanding of the logic behind the determination of mineral species, from a causal synthetic and genetic chemical system (based on an understanding of the genesis of the various types of mineral), as opposed to a system of classification based on the description of geometrical figures and on analytic decomposition.

${ }^{19}$ Homberg (1710: p. 428).
} 
Even when chemical and biological plants exhibit similar morphologies, the analogy also must, in order to be acceptable, be applicable to physiology and, even more strongly, to generation ${ }^{20}$. For Homberg, that is obviously not the case. He considers, instead, that the link between ancestor and descendent is needed for an explanation of the teleology of the generation of bodies as complex as those of plants.

\section{The Systême de la nature and the Introduction of Psychophysical Properties}

So far, I have uncovered some of the characteristics of Maupertuis' first conjecture, and some of the specific problems which have led him to revise it into the more refined theory we may find in his Systême de la nature (1751). This transition is what I now intend to examine, in light of all which has been previously discussed.

In the final segment of the Vénus, Maupertuis presents a series of doubts and questions which already hint at the limitations of the chemical-dynamic model for organic generation. Dissatisfied with his own "sketched-out system", the author tentatively raises the hypothesis of attributing an instinctive property to the seminal parts:

That instinct in animals which makes them seek that which is convenient to them, and escape from that which is harmful to them: does it not belong to the smallest parts of which an animal is formed? Wouldn't that instinct suffice, however dispersed it may be among the parts of the seeds, and weaker in each one individually than in the whole animal, to produce the required connections between these parts, as we see that, in fully formed animals, it causes their limbs to move? ${ }^{21}$

An affirmative answer to those questions characterizes the conceptual basis for the final theory of generation presented by Maupertuis in his Systême de la nature. It is constructed from an analogy unlike the one which compared the genesis of animals to arborescent crystallizations, an analogy in which two distinct genetic processes are lumped together at the level of vegetative functionality. Through an appeal to the concept of instinct, a new analogy is set in motion between the "relational life" characteristic of animal sensibility, connected to the higher functions of conservation in a mature animal, and an ontogenetic process. This analogy produces a significant theoretical shift, as, by means of an epistemological reduction of the most elementary dispositions of the seminal parts to the functionality of animal life, the generative model is associated to a more intrinsic teleology ${ }^{22}$. The general notion of instinct is intimately related to innateness and the sphere of internality. Whatever is relational in instinctive action is always connected to the preservation of an identity within a series of transformations. Let us examine, then, under which specific form Maupertuis articulates that general theoretical possibility in which a relational concept that is characteristic of animal life is associated to the material sphere of the ontogenesis of individual organisms.

Employing the same expository style previously found in the beginning of the Vénus, the Systême opens with a historical summary of the principles that physics adopted in succession, in its attempt to account for an everexpanding field of natural phenomena. Initially, extended matter and motion were considered sufficiently encompassing to explain the entirety of nature. Later, impenetrability, mobility and inertia are added. Finally, Newton argues for the inclusion of the principle of attraction. The postulation of special attractions or affinities allowed the explanation of a significant portion of chemical phenomena to be incorporated into that sequence. However, in the transition from the chemical to the organic, the cumulative scheme is interrupted: "However, even with such attractions, unless one supposes, so to speak, there to be as many of them as there are different parts in matter, we remain far from being able to explain the formation of a plant or an animal"23. As I have previously indicated, the articulation of the concepts of affinity and organic generation contains a limitation which, here, is made explicit. A reduction of genetic-organic dispositions intrinsic to chemical affinities would ultimately give them the same hidden-quality structure, for, in the explanation of the organization of bodies with growing complexity and diversity, chemistry would not present a limit for the multiplication of affinities, which was precisely the case in what concerned the internal virtues of things. Thus, a solution for that problem should

\footnotetext{
${ }^{20} \mathrm{~A}$ discussion of similar questions, but pertaining to the physiology of transport in vegetables, appears in.

${ }^{21}$ Maupertuis, (1965 [1768]: p. 131).

${ }^{22}$ For Duchesneau, this appeal to instinct in the final part of the Venus already presupposes the accretion of a monadological doctrine to the Newtonian model. He explains said accretion by identifying, in Maupertuis' conjecture, the use of occasional causes to establish the psychological determination of organic motion (1982: p. 248)—what I have termed an application of the register of life as relational and conservative to life conceived as vegetative and generative. This kind of determination would find its application in "the recombination of parts... in the organic structure, much like a combination of elementary projects connected to the instinctual and correlative activity of each part” (1982: p. 248). Such “elementary projects” may be understood by means of an analogy with the concept of perceptive and appetitive monads, or something equivalent. In my proposal, such elementary projects are understood as organic monads.

${ }^{23}$ Maupertuis (1965 [1768]: p. 141).
} 
not be sought in possible adjustments to the general idea of chemical affinity:

A blind and uniform attraction, diffused throughout all parts of matter, is unfit to explain how these parts arrange themselves to form the simplest of organized bodies. If they all share the same tendency, the same force that attracts them to one another, why do these come together to form an eye, while those form an ear? Why such an amazing combination? And why don't they all confusedly bond to one another? If something intelligible is to be said on the topic, even if it is to be merely understood on the basis of some analogy, an appeal must be made to some principle of intelligence, something similar to that which we name desire, aversion, memory ${ }^{24}$.

Having been prepared for it by the articulation between instinct and ontogenesis, the fundamental generative principle is no longer sought in the vicinity of the mineral and vegetable kingdoms, but in the more complex properties of animals and of humankind. The new analogy no longer operates with the material structure of metallic vegetation, but with the psychic structure at once related to the unity among beings endowed with sensibility and to their individuality. From this change a new explanatory model for generation springs forth, one that may be summarized as follows: instinct is understood as a seminal intelligence which attracts and repels organic parts so as to establish the necessary preferences which will produce the structure of the embryo. Once such a structure is produced, intelligence will adopt the function of genetic memory, perpetuating the form characteristic to the species from one generation to the next. The correct position which each part occupies in the organic whole may be once again adopted thanks to the memory which each particle is endowed with of their position in the ancestral organism. In the words of Maupertuis,

The elements which convene to form the fetus swim in the seeds of the paternal and maternal animals. Each one, however, extracted from a part similar to the one it must now form, preserves a kind of memory of its former situation, and will resume it as often as it can, so as to form an equal part in the fetus ${ }^{25}$.

Pangenesis-derived spermatogenesis and the mixture of the seeds as initial conditions for embryogenesis are preserved; nevertheless, the attribution of a mnemonic property to corpuscular seminal components adds an essential genetic feature which is acquired in spermatogenesis. The element in question is not merely a material organic form, but a representation of same. In my view, this allows for the interpretation that such seeds, endowed with psychic attributes, may be properly characterized by means of a general monadological model, Leibnizian in character.

\section{The Monadological Model and the Organic Monads}

By monadological model, I understand a conception where the constitution, formation and conservation of composite individuals, diverse or plural, is derived from discrete individuals, or monads, endowed with the ability to represent and express the organic character of a composite individual. These characteristics give monads an internal, spontaneous dynamics produced by a continual flux of transformations to the state of an original activity. By means of an application of the aforementioned model to Maupertuis' seminal parts, I will initially conceive them as physical monads, that is, elementary individuals in which psychic properties of a representational and expressive character, such as instinct, perception and memory, coexist with properties of a material or physical nature, such as mobility, impenetrability and attraction. As explained further down, I suggest, in addition, that these seminal parts are physical monads of a special kind, which I call organic monads. I have developed this interpretive hypothesis on the basis of François Duchesneau's understanding of the Systême de la nature as "an epigenetic conjecture founded on a physical monadology" ${ }^{26}$. According to the author, the term physical monadology, while contradictory in the context of Leibniz's doctrine, is appropriate for the characterization of an adherence to Leibniz's theory as peculiar and marginal as the one that appears in the Systême ${ }^{27}$. Unlike what one finds in Maupertuis' theory, in Leibniz's original monadology there could never be an 'agglomeration of parts, or a dissolution of organic compounds in nature, but only changes in the state of perceptive monads" ${ }^{28}$. Indeed, a natural philosophy consistent with such a monadology would reject the existence of true

\footnotetext{
${ }^{24}$ Maupertuis (1965 [1768]: p. 147).

${ }^{25}$ Maupertuis (1965 [1768]: p. 158).

${ }^{26}$ Duchesneau (1982: p. 236).

${ }^{27}$ Duchesneau (1982: p. 237).

${ }^{28}$ Duchesneau (1982: p. 238).
} 
generation or death for organized beings, save for supernatural creation and annihilation. What we inappropriately refer to as natural generation and death consist merely in the unfolding and contraction of an elementary structure which constantly maintains a primitive state of organization ${ }^{29}$. In order to bring these monadic structures conceptually closer to the seminal parts presented in the Système, I characterize the former as organic atoms or points, innately heterogeneous, which express the complete structure of an organism.

The concept of organic atom is present in the comparison between mathematical, physical and metaphysical points presented by Leibniz in his Système nouveaux de la nature: "when corporeal substances are compressed, all their organs together form but a physical point to our sight. Thus physical points are only indivisible in appearance". What we have here is a concept of divisible physical point or atom which is only contradictory when applied to a physics of homogenous extension, where indivisibility is a fundamental, albeit negative, characteristic. In the specific physics of organic generation, however, not based on figure or quantity, but on form and dynamics, an atom primarily displays two positive traits, totality and identity, established as a connection between organs. An organic monad is, fundamentally, that internally heterogeneous physical point, one in which an intimate connection exists between a morphology expressed materially as form and force, and a representational morphology expressed by a series of psychic attributes such as desire, memory, perception and instinct. It is in that sense that I conceive the seminal parts of the Systême as organic monads, and the theory of generation therein as an organic monadology ${ }^{30}$.

\section{The Connection between the Antagonistic Concepts of Epigenesis and Preformation}

Contrasted with the physical monad, the comparatively more specific characteristics of the concept of organic monad become evident when it is applied to an understanding of the generative process of living organisms. Thus, for the theory presented in the Système to be intelligibly established as an organic monadology, its relation to the concepts of epigenesis, preformation and preexistence must be determined. What I initially propose, then, is to effect a separation between the notion of epigenesis and the process of generation by means of the aggregation of preformed particles. Unlike what may be found in the work of a certain number of commentators ${ }^{31}$ a separation of that kind would no longer allow Maupertuis' theory of generation to be held as primarily epigenetic. For that end, I suggest that, as a characterization of epigenesis, an initial condition of homogeneity or nonorganic seminal simplicity is better than a formation of organs in succession during embryogenesis. We know that, in Maupertuis' theoretical conjecture, given the acceptance of pangenesis and the mixture of the seeds, the initial condition for generation is not homogenous. It possesses a double heterogeneity, namely that of the preformational structure of the isolated seminal parts, and that of the full assemblage of such parts produced by conception. In order to better determine the organic-monadological character of Maupertuis' theory, we must conceive of a generation by aggregation of parts in which the preformational aspect of the seed plays a primary role in the production of the complete and complex structure of the organism. With that in mind, I suggest that this role may be understood as a consequence of the psychic properties of the seminal parts, and each of the latter as an intelligible combination of a partial material preformation (corresponding to the various organs) with a global representational preformation ${ }^{32}$.

We may better understand such a proposition by, first, comparing this regional-universal combination in the

${ }^{30}$ While he does not use the expression, I believe Duchesneau also tends to think of Maupertuis' physical monad as a more specifically organic monad: "the physical monad is merely a functional unit of integration related to the specific and circumscribed experience of the phenomena of vital organization” (1982: p. 254).

${ }^{31}$ Roe (1981: p. 3, 13, 151); Terrall (2002: p. 222, 341); Fisher (2006: p. 105).

${ }^{32} \mathrm{~A}$ global organic structure within seminal parts merely partially preformed is, as I understand it, detected by Duchesneau as appearing in the final segment of the Vénus. For the author, "the dissolution of the organism might consist in a dissemination of parts capable of preserving their function, that is, their organic structuring property, the possibility being admitted of a new agglomeration of different parts so that an animal more or less divergent from the former may be born. However, the special functional character of this or that part makes it apt to enter into multiple combinations, all of them organically constituted. If it is possible to imagine that a part may produce all possible species depending on the combination of parts with which it may become united, then all possible forms must be present in the set of combinations corresponding to an organic order" (Duchesneau, 1982: p. 249). It is an extension of that combinatory register that brings a more particularly organic-monadological aspect to the seminal part. Going from the Vénus to the Système, Duchesneau identifies a specific organic constituent which confers intelligibility to the relations between whole and part proposed by Maupertuis' physical monadology: to the global-to-elementary analogy in operation between the whole and the part, or "to the relation of analogous functional properties existing between the global organism and the parts of which it is composed, a conception of organic order is appropriately added”, one of the monadological kind which “dictates to the author of the Système de la nature those concepts of order implied by his theory of living beings” (Duchesneau, 1982: p. 252).
} 
morphology of an organism to the substantial-relational combination previously discussed in the context of chemistry. In its relational aspect, affinity confers identity to the various chemical substances by placing them within a matrix of binary relations, as presented in a table of relations. I have considered this form of individuation as derived from an extrinsic combinatory order which establishes the center of a chemical substance by defining a sort of "neighborhood" for it. When the concept of chemical affinity is applied towards the explanation of a process of organic generation in which the formation of the seed happens through pangenesis, the said neighborhood is determined from the global morphology of ancestral organisms. That means that the determination of a local neighborhood is no longer the result of an extrinsic combinatory order, as was the case with chemistry, but rather of a participation in the internal morphology of a singular organic whole. In the context of the specific theory of generation found within the Système, that which was potentially substantial and internal in the disposition of chemical affinities becomes fully internal in the disposition of organic affinities.

For the most part, the theory present in the Système clearly adopts the position that both the preformation of material morphology and that of its representation are partial. However, from what I have hitherto discussed, it seems to me that this theory allows for a consistent extrapolation towards the conjecture that representation is partial only in relation to the organic form that is effectively active in embryogenesis, which is restricted to the vicinity of the location the seminal part occupies in the organic structure as a whole. Said active part would extend in unbroken continuity from the global representation associated with the seminal elements, and it is precisely that continuity which authorizes the transition from partial material morphology to global representational morphology ${ }^{33}$. With that conjecture, the preformational scheme may be associated to a concept of generation by means of the aggregation of seminal corpuscles, one which neither corresponds to a process of epigenesis from a single homogenous seed nor to simple growth by mechanical intussusceptions of a single corpuscle in the form of a materially complete embryo. This model allows the concept of preformation to be used as an organizing principle uncompromised by the aporias which commonly result from notions present in global preformation, such as embedded germs and monoparental contribution. It is precisely under such conceptual relations that what I initially referred to as an alliance between epigenesis and preformation emerges.

Conclusion and final considerations: pre-existence, origin of life and transformism.

These are, in short, the more immediate results brought about by a characterization of the theory presented in the Système as an organic monadology. There is, however, yet another meaningful effect produced by such a characterization. The concept of global morphological representation associated to the seminal parts "attracts" the concept of germ preexistence back into Maupertuis' theory. As we have done in relation to the concepts of epigenesis and preformation, the focus of the concept of preexistence may be shifted towards an adoption of the term's literal meaning as its main characteristic: an existence that is previous, previous not merely to embryogenesis, to the mixture of the seeds or to spermatogenesis, but previous even to the birth of any progenitors, independently of whether preformation is understood as partial or complete. That shift in our conceptual focus enables us to find, in the Système, a clear link to the notion of germ preexistence, not in its study of the ordinary genesis of organisms in genealogical succession over time, but in its bold ideas concerning the genesis of the first organisms. The hypothesis of the existence of complete preexisting germs, naturally impossible to engender or destroy, had already been raised by Maupertuis in the Vénus, which indicates the existence of an affinity between his ideas and Leibniz's original monadology, understood as a kind of panspermia:

Is that instinct, like the spirit of a Republic, distributed among all the parts which convene to form the body? Or, much like in a monarchic State, does it belong exclusively to some indivisible part? If the latter, would this part be that which properly constitutes the essence of the animal, with all others being merely husks or raiments of some sort? [...] Wouldn't this part survive death? And, freed from all others, inalterably preserve its essence? Always ready to produce an animal, or, to put it more accurately, to reappear garbed with a new body after having been dissipated in air or water, hidden in the leaves of plants or the flesh of ani-

\footnotetext{
${ }^{33}$ I believe this association between a global morphological representation and a partial and material morphological expression in the seminal particles may ultimately characterize Maupertuis' system as a vitalist materialism, as proposed by Zammito (2006: p. 324, 331, 336). Despite there being a large variety of positions involved in the substantial articulation between that which is material and that which is vital, the author's position seems fundamentally derived from an identification between activity and vitality (p. 331). Despite its meritorious uncovering of a connection between vitalist materialism and hylozoism, and between these and monadology (p. 333), such an interpretation requires the activity and vitality of seminal parts to be responsible for a kind of generation whose materialistic character appears in the guise of self-organization. The latter substantiates the strong association between epigenesis and generation by means of the aggregation of seminal particles, which to me seems inadequate once one accepts the pangenetic origin of said particles.
} 
mals, wouldn't it find itself once again within the seed of the animal it is meant to recreate? ${ }^{34}$

In the Système this hypothesis is once again raised, but with a significant alteration: scattered across the "environment”, these seeds are preexisting germs, endowed with psychic attributes but only partially preformed in a material sense. Thus understood, Maupertuis employs these germs to paint a picture of the origins of life made up of a primordial and universal set of seeds which, much like the local mixture which occurs in every ordinary generation, started to convene to form the first generation of organized beings:

[...] everything leads us to believe that all the matter we see on the surface of our Earth has once been fluid, whether from having been dissolved in water, whether from having been fused by fire. Well, when the materials of our globe were in such a state of fluidity, they found themselves in the same situation as these liquids in which swim the elements bound to produce animals. And the metals, the minerals, the precious stones were much more easily formed than even the least organized insect. The least active parts of matter would have formed the metals and the minerals; the most active, animals and $\operatorname{man}^{35}$.

Yet while this image of the primordial origins possesses strong naturalistic or even materialistic characteristics, it must necessarily be the product of supernatural creation:

$[\ldots]$ if he [God] endowed each of the smallest parts of matter, every single element, with some property similar to what in ourselves we name desire, aversion, memory, having been miraculous the formation of the first living individuals, those that succeeded them are no longer but the effects of these properties. The elements particular to each body, when in large enough quantities and sufficiently near to one another that their actions are possible, will convene so as to continually provide the universe with what it once had but $\operatorname{lost}^{36}$.

With his criticism of the systems of generation of his time, Maupertuis ends up concluding that "the first production in every system is a miracle"37. That leads us to consider that the internality and totality established for morphological determination no longer applies, and it reverts to a condition of being partial and external. The external order is derived not from the combinatory rules of chemical affinities, but a supernatural source. The importance of this second type of external order can be better understood if we consider, even briefly, how its known principle of least action would relate to a theory of strongly sustained organic generation in an internal monadological principle of order.

As a great final conclusion of your project in theoretical physics and cosmology, Maupertuis presented the proof that a supreme intelligence rules the universe. In order to find a more general principle that the attraction, which would reduce the most fundamental physical laws, the author incorporated, expanded and criticized elements of natural philosophy of Newton. This principle is linked to a metaphysical conception of God as a producer of laws capable of ensuring a general structure of the universe, and physically in one of the actions conservation law spent on production of phenomena whose total effect would be the maintenance of cosmological structure. This is the principle of least action: when there is some change in the nature, the amount of action required for such a change is as small as possible. Maupertuis found, to the physics of his time, the amount of action, defined as the product of the mass of the bodies for its velocity and space traversed, is the real physical quantity economically spent in nature. With the mathematical expression of this principle the author intended have deduced the laws of optics, of rest and motion of bodies. At the same time when drawing up the Vénus, the successful application of the principle in theoretical physics led the author, as he wrote in 1746, to "derive from the same source truths of a superior gender and most important, namely, to seek evidence of the existence God in the general laws of nature"38.

The metaphysical notion underlying physical principle of least action and establishing God's relationship with nature is, briefly, the following "all things are ordered in such a way that a blind and necessary Mathematics performs what the most intelligence enlightened and the freest prescribes”39. Such a concept would articulate the wisdom and the divine power and, most importantly, ensuring a degree of autonomy of nature but is at the same

\footnotetext{
${ }^{34}$ Maupertuis (1965 [1768]: pp. 132-133).

${ }^{35}$ Maupertuis (1965 [1768]: p. 169).

${ }^{36}$ Maupertuis (1965 [1768]: p. 157).

${ }^{37}$ Maupertuis (1965 [1768]: p. 157).

${ }^{38}$ Maupertuis (1985 [1746]: p. 103).

${ }^{39}$ Maupertuis (1985 [1746]: p. 114).
} 
time, subject to the will of God. For Maupertuis, "One cannot doubt that all things are not governed by a supreme being that while printed at matter forces denoting its power, destined it to perform effects that mark their wisdom, ${ }^{, 0}$. The regularity of the phenomena revealed in the law is, ultimately, an effect of the remote action of God in Nature. This action follows a metaphysical principle of simplicity whose phenomenal expression would be the economy of the amount of action expended in the production of phenomena.

The relationship of the least action principle to the theory of organic generation can be examined from the connection that, in the Maupertuis' physics, exist between the first and the principle of attraction. In Vénus Physique, we have seen that the attraction is a key entity in the generation explanation. Compared to monadological principles allies to internal psychophysical properties of the seminal parts, the principle of attraction would be, as the basis of physical properties, more easily deductible from the principle of least action. The effects produced by the attraction between the general bodies would be under the regulation of this principle and both pangenetics phenomena of seed production as the aggregation of the seminal parts would be a particular case of this phenomenon. In the process of attraction of these parts there would be a economy of expended action for the formation of organisms and thus from the principle of least action, it would be possible to explain all generative phenomena. However, Maupertuis not explored the link between the principle of least action and the law of attraction of bodies as it did for other general laws of physics. As stated Beeson, "After his revolutionary work in the years 1730, Maupertuis left further work on the Newtonian theory to Euler, d'Alembert and Clairaut” ${ }^{\star 41}$. In Lettre XII. Sur l'attration can see the position in this regard:

We show that all the laws of motion were founded on the principle of minimum amount of action: Newton showed that all celestial bodies move through an attraction toward the sun: and M. Euler found that the bodies move by a force that continually attracts toward a center, they employ on their routes the minimum amount of action as possible. Here we can refuse admiration? We cannot be touched with the agreement of these different laws? If we do not see the attraction itself depends on the principle of minimum amount of action, at least its effects are subordinate to them: it makes the body move, as it is necessary that they move to comply with this universal law of Nature ${ }^{42}$.

According to Beeson, this letter establishes a bridge between the two main areas of Maupertuis' work in physics and, from the results of Euler published in his Methodus inveniendi lineas curves, "Attraction theory and least-action principle are therefore inextricably linked at the cosmological level at least" ${ }^{* 3}$. However, commenting on the same quote, Tonelli says that even seeking to extend as far as possible that the principle of least action, Maupertuis avoided committing imprudences and "tried not to apply [the principle of least action] to biological phenomena” ${ }^{44}$. In fact, we not see this attempt in his work but in spite of prudence stressed by Tonelli and restriction to the cosmological context emphasized by Beeson, I believe that the previous text of the Lettres shows that Maupertuis believed that the effects produced the attraction in general bodies were regulated by the principle of least action, although he did not attempt to demonstrate it himself $f^{45}$.

After these considerations, we can return to the types of systems of organic generation identified by Maupertuis and understand why, among them, which is more in line with your ideas is one in which "the very elements, imbued with intelligence, arrange and convene in Themselves order to bring about the Creator's ends". That way, the global representational function of the mnemonic properties of the seminal parts interrupts the genetic continuity present in the ancestor-descendent link and is thus diluted in an origin derived from special creation. In Maupertuis' system, nevertheless, this creation produces merely the most fundamental element of organic di-

\footnotetext{
${ }^{40}$ Maupertuis (1974 [1768]: p. 21).

${ }^{41}$ Beeson (1992: p. 248).

${ }^{42}$ Maupertuis (1965 [1768]: p. 288-289).

${ }^{43}$ Beeson (1992: p. 248).

${ }^{44}$ Tonelli (1987: p. 46).

${ }^{45}$ I think, whit a monadological model of the theory of generation, that has as main explanatory principle the postulation of a internal source of morphological and teleological order, is no longer necessary to use the principle of least action to explain the organic generation. However, we could speculate if there was another way, that is, if it would be possible to consider the validity of the principle of least action in the actions economy to phenomena in which the psychic properties have a primary explanatory role. In Les lois du movement et du repos rapid consideration is made in this direction: "The laws of motion and rest so deducted [from the principle of least action and the attributes of God are precisely the same as those observed in nature: we can admire its application in all phenomena: the movement of animals, plants and vegetation in the revolution of the Stars” (Maupertuis, 1985 [1746]: p. 121). It is not the attraction that appears here, but the laws of movement by shock, considered in Vénus unable to explain any of biological phenomena treated by Maupertuis. However, here they are corrected and perfectly integrated under the principle of least action and, for this reason, the author may have glimpsed without developing a possibility of building a theory that integrates the astronomical and biological phenomena.
} 
versity, leaving a considerable part of the work to nature. This natural, creative genetic effect will be expressed in the specific concepts of accident and modification of races and species which, in Maupertuis' theory, come together under the general umbrella of transformism. The relationship between this particular conceptual domain and problems pertaining to organic monadology is, however, a theme for future studies ${ }^{46}$.

\section{References}

Aristotle (1953). Generation of Animals. London: William Heinemann, The Loeb Classical Library.

Beeson, D. (1992). Maupertuis: An Intellectual Biography. Oxford: The Voltaire Foundation at the Taylor Institution.

Bergman (1788). Traité des affinités chymiques ou attractions électives. Paris: Buisson.

Duchesneau, F. (1982). La Physiologie des Lumières. Empirisme, modèles et theories. Boston: The Hague.

Fisher, S. (2006). The Soul as Vehicle for Genetic Information: Gassendi’s Account of Inheritance. In J. E. H. Smith (Ed.), The Problem of Animal Generation in Early Modern Philosophy (pp. 103-123). Cambridge: Cambridge University Press.

Geoffroy, M. (1770). Table des différents rapports observés en Chimie entre différentes substances. In J. Berray et al. (Eds.)., Collection académique (pp. 149-155). Paris: Pancrouke.

Hippocrates (1981). On Generation. In I. M. Lonie (Ed.), The Hippocratic Treatises "On Generation”, "On the Nature of the Child”, “Diseases IV”: A Commentary (pp. 1-5). Berlin/New York: Gruyder.

Hippocrates (1992). The Sacred Disease. In G. P. Goold (Ed.), Hippocrates II (139-183). Cambridge: Harvard University Press, The Loeb Classical Library.

Homberg, G. (1710). Mémoire touchant les vegetations artificielles. Mémoires de l'Académie Royale des Sciences, $426-438$.

Leibniz, G. W. (1994). Système nouveau de la nature et de la communication des substances aussi bien que de l'union qu'il y a entre l'âme et le corps. In Systéme nouveau de la nature et de la communication des substances et autres textes: 16901703 (pp. 61-90). Paris: Flammarion.

Leibniz, G. W. (1996). Principes de la philosophie [monadologie]. In Principes de la nature et de la grâce, Monadologie: Et autres textes: 1703-1716 (pp. 241-268). Paris: Flammarion.

Maupertuis, P.-L. M. de. (1965 [1768]). Oeuvres (vol. II). Hildesheim: Georg Olms.

Maupertuis, P.-L. M. de. (1985). El orden verosímil del cosmos. Madrid: Alianza.

Metzger, H. (1974). Newton, Stahl, Boerhaave et la doctrine chimique. Paris: Albert Blanchard.

Mocellin, R. C. (2006). A química newtoniana. Química Nova, 29, 388-396. http://dx.doi.org/10.1590/S0100-40422006000200035

Roe, S. A. (1981). Matter, Life, and Generation: Eighteenth-Century Embryology and the Haller-Wolff Debate. Cambridge: Cambridge University Press.

Shank, J. B. (2008). The Newton Wars and the Beginning of the French Enlightenment. Chicago, IL: University of Chicago Press. http://dx.doi.org/10.7208/chicago/9780226749471.001.0001

Smith, J. E. H. (2006). Introduction. In J. E. H. Smith (Ed.), The Problem of Animal Generation in Early Modern Philosophy (pp. 1-18). Cambridge: Cambridge University Press. http://dx.doi.org/10.1017/CBO9780511498572.001

Terrall, M. (2002). The Man Who Flattened the Earth: Maupertuis and the Sciences in the Enlightenment. Chicago, IL: University of Chicago Press. http://dx.doi.org/10.7208/chicago/9780226793627.001.0001

Tonelli, G. (1987). La pensée philosophique de Maupertuis: Son milieu et ses sources. Hildesheim: Georg Olms.

Zammito, J. (2006). Kant's Early Views on Epigenesis: The Role of Maupertuis. In J. E. H. Smith (Ed.), The Problem of Animal Generation in Early Modern Philosophy (pp. 317-354). Cambridge: Cambridge University Press.

http://dx.doi.org/10.1017/CBO9780511498572.015

\footnotetext{
${ }^{46}$ The presence of supernatural preexistence in an organic monadology which, as is the case with Maupertuis', is critical of the concepts of embedment, monoparental heritage and the fixity of species, may be investigated with what Zammito regards as a reformation of the physical theology promoted by Maupertuis (2006: p. 328) as a starting point. In it, there is supposed to be a lessening of the anthropocentrism associated to an appeal to the "wonders of nature".
} 